\title{
Laboratory diagnosis of Clostridium perfringens antibiotic-associated diarrhoea
}

\author{
N. J. ASHA and M. H. WILCOX \\ Department of Microbiology, Leeds General Infirmary and University of Leeds, Leeds LS1 3EX
}

\begin{abstract}
Clostridium perfringens has been reported as the cause of up to $15 \%$ of cases of antibiotic-associated diarrhoea (AAD) and may be diagnosed by detection of enterotoxin (CPEnt) in faeces. The performance of a commercial ELISA method for CPEnt, with culture and PCR methods to confirm the presence of enterotoxigenic $C$. perfringens, was evaluated in 200 consecutive specimens from patients with clinical details suggestive of AAD: $8 \%$ of the specimens were positive for CPEnt, $16 \%$ were positive for $C$. difficile cytotoxin and $2 \%$ gave positive test results for both $C$. perfringens and $C$.difficile toxins. Culture and PCR results confirmed the majority of ELISA results, although $2(12.5 \%)$ reactive specimens were only weakly positive. $C$. perfringens is a potentially important cause of infective AAD and can be detected with the $C$. perfringens enterotoxin ELISA kit, although weak positive results should be considered with caution.
\end{abstract}

\section{Introduction}

Clostridium perfringens was first implicated as a cause of antibiotic-associated diarrhoea (AAD) in 1984 [1], when free faecal $C$. perfringens enterotoxin (CPEnt) was detected in 11 patients with diarrhoea following antibiotic administration. The evidence for a causal role by $C$. perfringens in AAD has increased and it has been reported to account for between $2 \%$ and $15 \%$ of all cases [1-4]. CPEnt is a $35-\mathrm{kDa}$ protein produced constitutively in vivo at low levels by bacteria during the vegetative growth phase, but expression is upregulated during sporulation $[5,6]$. CPEnt binds to gut epithelial cells, where it is internalised and alters cell membrane permeability, with resultant epithelial cell death leading to diarrhoea. Unlike $C$. difficile infection, $C$. perfringens AAD does not result in the formation of pseudomembranes [1]. CPEnt is encoded by the cpe gene which has been cloned and sequenced [5], and this has permitted the design of amplification primers $[7,8]$. A study of C. perfringens isolates showed that only $6 \%$ of wild-type strains possess the cpe gene [8], although the prevalence of such strains in infected symptomatic patients with food poisoning is much higher [9].

Received 6 March 2002; revised version received 21 May 2002; accepted 4 June 2002.

Corresponding author: Dr M. H. Wilcox

(e-mail markwi@pathology.leeds.ac.uk).
CPEnt can be detected in faecal specimens by the Vero cell cytotoxicity assay or ELISA systems [1,10-12]. Culture of $C$. perfringens is not recommended as a diagnostic method, given the relative ubiquity of the bacterium in human faeces, and because not all isolates will be enterotoxigenic. CPEnt production from cultured isolates can be difficult to demonstrate because it occurs during sporulation and it is difficult to make this bacterium sporulate in vitro [8]. An ELISA method for the detection of CPEnt has been developed (TechLab, Blacksburg, USA) although the performance characteristics of this kit have not been fully evaluated. We have demonstrated previously that there are problems with the culture of enterotoxigenic $C$.perfringens from faecal specimens found to be CPEnt ELISA positive [3]. Therefore, this study aimed to determine the relative frequencies of $C$. perfringens and $C$. difficile $\mathrm{AAD}$, and to validate results obtained with the CPEnt ELISA kit by culture, a cytotoxin assay and a nested PCR method to enhance sensitivity.

\section{Materials and methods}

\section{Specimens}

Two hundred consecutive faecal specimens from inpatients submitted for $C$. difficile testing at Leeds Teaching Hospitals Trust were studied for evidence of C. perfringens infection. All patients had diarrhoeal stools and clinical evidence of AAD. Only specimens 
$<24 \mathrm{~h}$ old were eligible for inclusion. All specimens were stored at $4^{\circ} \mathrm{C}$ before testing.

\section{Cytotoxin detection}

C. difficile cytotoxin was detected with Vero cells and C. difficile antitoxin (TechLab) and the same Vero cell assay was used to detect $C$. perfringens enterotoxin with $C$. perfringens enterotoxin antitoxin (TechLab) as described previously [1]. Faecal supernate was added undiluted to the test wells (in-well dilution 1 in 10). The assays were repeated with a 1 in 10 dilution of the faecal preparation if evidence of bacterial overgrowth or non-specific cytotoxicity was apparent on reading the wells. The $C$. perfringens Enterotoxin Test kit (TechLab, distributed by BioConnections, Leeds, W. Yorks) was used according to the manufacturer's instructions and results were available within $2.5 \mathrm{~h}$. Results were recorded with a dual-wavelength spectrophotometer $(450 \mathrm{~nm}$ and $620 \mathrm{~nm})$ as recommended, as this was found to be preferable to visual interpretation of results.

\section{C. perfringens culture}

Two Robertson's cooked meat broths (Oxoid) were inoculated with each specimen, one direct and one after alcohol shock treatment [13], and incubated aerobically for $24 \mathrm{~h}$ at $37^{\circ} \mathrm{C}$. The broths were subcultured on to egg yolk agar (Oxoid) and neomycin blood agar (Oxoid) with a $5-\mu \mathrm{g}$ metronidazole disc (Oxoid) and incubated anaerobically overnight at $37^{\circ} \mathrm{C}$. Identification of $C$. perfringens colonies was by reaction with $C$. perfringens type A antitoxin (TechLab) and Gram's stain. Up to three $C$. perfringens colonies from each culture plate were stored at $-20^{\circ} \mathrm{C}$ in phosphate-buffered saline with glycerol $40 \%$.

\section{PCR detection of the cpe gene}

DNA was extracted directly from each faecal specimen with the QIAamp ${ }^{\circledR}$ DNA Stool Mini Kit (QIAGEN, Crawley, UK) according to the manufacturer's instructions. DNA extracts were stored at $-20^{\circ} \mathrm{C}$ before PCR. After thawing, extracted DNA was added directly to the PCR assay as template. For PCR of $C$. perfringens isolates, stored isolates were cultured on neomycin blood agar. One colony was suspended in $50 \mu \mathrm{l}$ of sterile distilled water and heated to $99^{\circ} \mathrm{C}$ for $5 \mathrm{~min}$. This suspension was used as template in the PCR.

A nested PCR technique was used with faecal DNA extracts, but the second round primers were used alone with extracts prepared from isolates. The first round primers were 5'-TGTTAATACTTTAAGGATATGTAT CC-3' and 5'-TCCATCACCTAAGGACTG-3' as described by Kokai-Kun et al. [7]. Each 25- $\mu$ l PCR reaction contained $10 \mathrm{pmol}$ of each primer, buffer, $2 \mathrm{mM} \mathrm{MgCl}_{2}, 0.2 \mathrm{mM}$ dNTPs, $1 \mathrm{U}$ of Taq polymerase (Promega UK, Southampton) and $2.5 \mu \mathrm{l}$ of template
DNA. The reaction comprised $5 \mathrm{~min}$ at $94^{\circ} \mathrm{C}$ followed by 34 cycles of $1 \mathrm{~min}$ at $94^{\circ} \mathrm{C}, 1 \mathrm{~min}$ at $50^{\circ} \mathrm{C}$ and $1 \mathrm{~min}$ at $72^{\circ} \mathrm{C}$. There was a final extension step of $10 \mathrm{~min}$ at $72^{\circ} \mathrm{C}$. The PCR product was used as template for the second round PCR. Second round primers were 5'ATGTAATAGATAAAGGAGATGGTT-3' and 5'-ATAA ATTCAGAAGTAAATCCAACT-3' as described by Van Damme-Jongsten et al. [8,14]. Each 25- $\mu$ l PCR reaction contained $10 \mathrm{pmol}$ of each primer, buffer, $3 \mathrm{mM}$ $\mathrm{MgCl}_{2}, 0.2 \mathrm{mM}$ dNTPs, $1 \mathrm{U}$ of Taq polymerase and $2.5 \mu \mathrm{l}$ of template DNA. The reaction comprised $5 \mathrm{~min}$ at $95^{\circ} \mathrm{C}$ followed by 45 cycles of $30 \mathrm{~s}$ at $94^{\circ} \mathrm{C}, 30 \mathrm{~s}$ $50^{\circ} \mathrm{C}$ and $30 \mathrm{~s}$ at $70^{\circ} \mathrm{C}$. The PCR product was $163 \mathrm{bp}$. The enterotoxigenic C. perfringens strain NCTC 8239 was used as the positive control for the PCR assays.

\section{Results}

The prevalence of $C$. difficile infection in the study group was $16 \%$.

Fig. 1 summarises the results of the CPEnt ELISA, cpe PCR testing and $C$. perfringens culture. Sixteen (8\%) of faecal specimens gave positive test results for CPEnt with the ELISA kit. Four of these 16 specimens were also positive in the Vero cell assay. Of the ELISApositive specimens, 14 were cpe positive by nested PCR of faecal DNA extracts; 12 of these specimens yielded cpe-positive C. perfringens on culture. Of the two ELISA-positive PCR-negative specimens, only one specimen yielded $C$. perfringens on culture and none of the colonies tested was cpe positive. Four of the ELISA-positive specimens were also positive for C. difficile infection.

Of the 200 specimens, 184 were both ELISA and Vero cell assay negative; 177 (96\%) of these specimens were cpe-negative by nested PCR of faecal DNA extracts. A total of $267 C$. perfringens isolates from these specimens were stored, and $20 \%$ of isolates were randomly selected for further PCR analysis. Of these randomly selected isolates 7 (13\%) were cpe positive. Seven (4\%) of the ELISA-negative specimens were cpepositive by nested PCR of faecal DNA extracts. Five of these seven specimens yielded $C$. perfringens on culture, but only two contained cpe-positive isolates.

\section{Discussion}

Although $C$. difficile is the most commonly identified pathogen in hospital-acquired infective diarrhoea, the cause(s) of the majority of the cases, in some series up to $80 \%$, currently remain undiagnosed. Staphylococcus aureus and $C$. perfringens are the most frequently cited alternative causes of AAD [15]. In the present study, $8 \%$ of the study population were found to be CPEnt positive according to ELISA results. This compares with a $16 \%$ prevalence rate of $C$. difficile infection in 


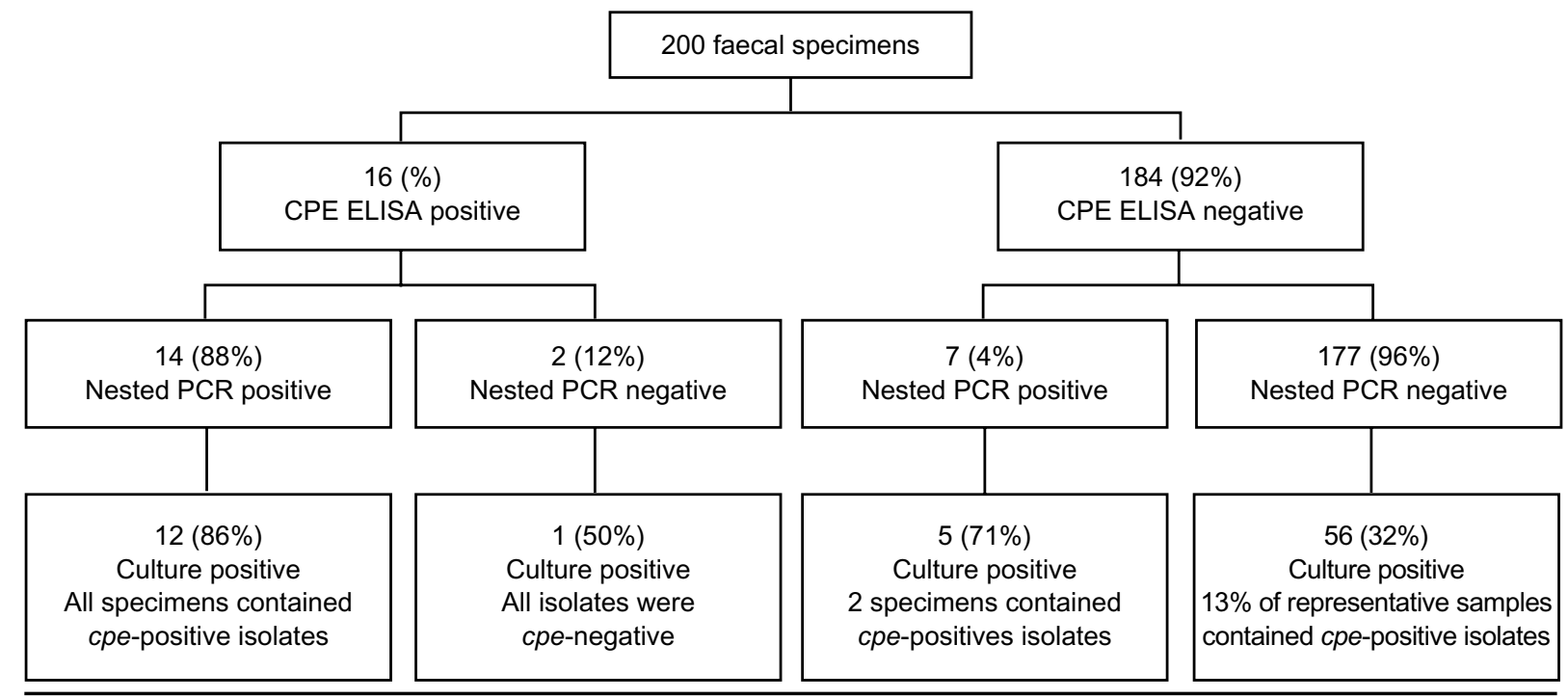

Fig. 1. Summary of results of CPEnt ELISA, cpe PCR testing, and C. perfringens culture.

the same group. One quarter of the CPEnt-positive specimens $(2 \%$ overall), were also positive for $C$. difficile cytotoxin. In 14 of the 16 ELISA-positive specimens there was further evidence of enterotoxigenic $C$. perfringens from a cytotoxin assay, nested PCR on faeces for cpe, and culture with direct PCR for cpe. It is important to note that nearly half of those specimens containing cpe-positive isolates also contained cpe-negative isolates. This suggests that multiple colonies need to be tested from each sample. Investigations on two of the ELISA-positive specimens failed to provide any further supporting evidence for infection. It is of interest that these two specimens produced the lowest OD results obtained in the ELISApositive group, and this was confirmed by repeat testing. Because the ELISA kit has a single cut-off point for results, there is no grey zone for equivocal results. We believe that these two specimens were false-positive results in the absence of further evidence of infection. As such, CPEnt-positive results that are only slightly higher than the ELISA kit cut-off should be treated with caution. Furthermore, only those specimens that produced a positive ELISA reading greater than that obtained for the positive control were detectable in the Vero cell assay. Therefore, we conclude that the ELISA kit is much more sensitive than the Vero cell assay for the detection of CPEnt, and indeed that use of the latter assay alone will fail to identify the majority of CPEnt-positive infections.

The ELISA-negative PCR-positive samples may represent a group of patients who are carrying enterotoxigenic $C$. perfringens but in whom CPEnt is not produced. Thus, the cpe gene may be present but not expressed. Alternatively, CPEnt may not be captured by the ELISA system, for example, if it was a modified toxin or neutralised by host factors [16]. The 13\% cpepositive $C$. perfringens rate seen with isolates from the ELISA-negative faecal DNA PCR-negative specimens may reflect the prevalence of cpe-positive isolates in this group of patients. Although it is higher than the $6 \%$ rate previously reported [8], this may be expected in a symptomatic patient cohort. Some of these patients may have had earlier CPEnt-mediated diarrhoea that has since resolved. Such faecal specimens probably failed to yield cpe-positive nested PCR results because of low organism load, which was aided by enrichment of enterotoxigenic $C$. perfringens.

A previous study in this hospital with the CPEnt ELISA kit found that $15 \%$ of patients with AAD were CPEnt positive [3]. While this appears considerably higher than the $8 \%$ prevalence rate found in the current study, it was consistent with the similarly higher prevalence of $C$. difficile cytotoxin (32\%) in the tested specimens. The prevalence of the cpe gene in $C$. perfringens isolates from ELISA-negative faeces in the previous study was $10 \%$, a figure similar to that identified in the current study. The preliminary study highlighted discrepancies between ELISA results and the isolation of enterotoxigenic $C$. perfringens, with $68 \%$ of isolates from ELISA-positive samples lacking the cpe gene. As in the current study, testing of multiple colonies demonstrated that specimens could contain a mixture of cpe-positive and cpe-negative strains. To overcome these problems in the current study, PCR was used to demonstrate the presence of the cpe gene directly from the faecal specimen.

Evaluation of the PCR method with quantitative techniques to spike faeces with $C$. perfringens broth indicated that the use of a nested PCR protocol could increase the test sensitivity from $8 \times 10^{8} \mathrm{cfu} / \mathrm{g}$ faeces to $<80 \mathrm{cfu} / \mathrm{g}$ of faeces (unpublished data). This was essential for the detection of the cpe gene in faecal DNA extracts that may contain low numbers of enterotoxigenic $C$. perfringens. Several methods have been described for the detection of CPEnt in faeces, 
including tissue culture assays, ELISA and RPLA [4]. Vero cell tissue-culture assay has been reported to lack sensitivity (40 $\mathrm{ng}$ of enterotoxin/g of faeces) and reproducibility for the detection of CPEnt [16] and this was observed during the present study. Some workers have suggested that the gold standard test for CPEnt in faeces should be an in-house ELISA developed by the PHLS Central Food Laboratory, because of its high sensitivity (5 $\mathrm{ng}$ of enterotoxin/g of faeces), specificity and reproducibility [16]. However, the development of a similar system in most diagnostic laboratories is not feasible. An RPLA kit is commercially available (Oxoid) and, although sensitive and reproducible, non-specific reaction with faecal matter has been recorded [17].

Because $C$. difficile AAD may markedly prolong hospital stay, it is plausible that $C$. perfringens AAD may also result in extended hospitalisation, particularly in frail elderly patients. There is also some evidence that treatment of $C$. perfringens AAD with metronidazole can produce symptomatic benefit [18]. Therefore, there may be justification to support the routine detection by laboratories of CPEnt in faecal specimens. Resources released from abandoning the routine examination of faecal specimens for (non- $C$. difficile) conventional bacterial enteropathogens in patients who develop diarrhoea after day three of admission could be redirected to CPEnt testing [19]. Alternatively, CPEnt testing could be reserved for those faecal specimens found to be $C$. difficile toxin-negative. We conclude that $C$. perfringens is a potentially important cause of infective AAD and can be reliably detected with the TechLab $C$. perfringens enterotoxin ELISA system, although weakly positive results should be considered with caution.

We thank TechLab Inc. for kindly providing the $C$. perfringens Enterotoxin Test kits and C. perfringens antitoxin. We also thank staff in the routine enteric laboratory at Leeds Teaching Hospitals Trust for conducting the CPEnt cytotoxin assays.

\section{References}

1. Borriello SP, Larson HE, Welch AR, Barclay F, Stringer MF, Bartholomew BA. Enterotoxigenic Clostridium perfringens: a possible cause of antibiotic-associated diarrhoea. Lancet 1984; i: $305-307$.

2. Hancock P. Antibiotic associated diarrhoea: Clostridium difficile or C. perfringens? Rev Med Microbiol 1997; 8 Suppl 1: S66-S67.

3. Ransome NJ, Fitzgerald P, Wilcox MH. Antibiotic associated diarrhoea and Clostridium perfringens enterotoxin. 38th Interscience Conference on Antimicrobial Agents and Chemotherapy, San Diego, 1998. Abstract K126.

4. Modi N, Wilcox MH. Evidence for antibiotic induced Clostridium perfringens diarrhoea. JClin Pathol 2001; 54: $748-751$.

5. Czeczulin JR, Hanna PC, McClane BA. Cloning, nucleotide sequencing, and expression of the Clostridium perfringens enterotoxin gene in Escherichia coli. Infect Immun 1993; 61: 3429-3439.

6. Czeczulin JR, Collie RE, McClane BA. Regulated expression of Clostridium perfringens enterotoxin in naturally cpe-negative type $\mathrm{A}, \mathrm{B}$, and $\mathrm{C}$ isolates of $C$. perfringens. Infect Immun 1996; 64: 3301-3309.

7. Kokai-Kun JF, Songer JG, Czeczulin JR, Chen F, McClane BA. Comparison of Western immunoblots and gene detection assays for identification of potentially enterotoxigenic isolates of Clostridium perfringens. J Clin Microbiol 1994; 32: $2533-$ 2539.

8. Van Damme-Jongsten M, Wernars K, Notermans S. Cloning and sequencing of the Clostridium perfringens enterotoxin gene. Antonie Van Leeuwenhoek 1989; 56: 181-190.

9. Van Damme-Jongsten M, Rodhouse J, Gilbert RJ, Notermans S. Synthetic DNA probes for detection of enterotoxigenic Clostridium perfringens strains isolated from outbreaks of food poisoning. J Clin Microbiol 1990; 28: 131-133.

10. McClane BA, Strouse RJ. Rapid detection of Clostridium perfringens type A enterotoxin by enzyme-linked immunosorbent assay. J Clin Microbiol 1984; 19: 112-115.

11. Bartholomew BA, Stringer MF, Watson GN, Gilbert RJ. Development and application of an enzyme linked immunosorbent assay for Clostridium perfringens type A enterotoxin. $J$ Clin Pathol 1985; 38: 222-228.

12. Giugliano LG, Stringer MF, Drasar BS. Detection of Clostridium perfringens enterotoxin by tissue culture and double-gel diffusion methods. J Med Microbiol 1983; 16: 233-237.

13. Larson HE, Borriello SP. Infectious diarrhea due to Clostridium perfringens. J Infect Dis 1988; 157: 390-391.

14. Daube G, China B, Simon P, Hvala K, Mainil J. Typing of Clostridium perfringens by in vitro amplification of toxin genes. J Appl Bacteriol 1994; 77: 650-655.

15. Wilcox MH. Infective antibiotic-associated diarrhoea. In: Wilcox MH (ed) Infection highlights 1999-2000. Oxford, Health Press. 2000: 57-64.

16. Birkhead G, Vogt RL, Heun EM, Snyder JT, McClane BA. Characterization of an outbreak of Clostridium perfringens food poisoning by quantitative fecal culture and fecal enterotoxin measurement. J Clin Microbiol 1988; 26: 471-474.

17. Berry PR, Rodhouse JC, Hughes S, Bartholomew BA, Gilbert RJ. Laboratory techniques. Evaluation of ELISA, RPLA, and Vero cell assays for detecting Clostridium perfringens enterotoxin in faecal specimens. J Clin Pathol 1988; 41: 458-461.

18. Borriello SP, Barclay FE, Welch AR et al. Epidemiology of diarrhoea caused by enterotoxigenic Clostridium perfringens. $J$ Med Microbiol 1985; 20: 363-372.

19. Wood M. When stool cultures from adult inpatients are appropriate. Lancet 2001; 357: 901-902. 